\title{
Kardan mili üzerinden tork ölçme sistemi tasarımı ve üretimi
}

\author{
Sedat TARAKÇI ${ }^{1,2, *}$, Oğuzhan ALDEMİR ${ }^{1}$, Efe IŞIK ${ }^{1}$, Serhan ÖZDEMİR ${ }^{2}$ \\ ${ }^{1}$ Tirsan Kardan San Tic A.Ş., Tirsan Kardan ArGe Merkezi, Manisa \\ ${ }^{2}$ İmir Yüksek Teknoloji Enstitüsü, Mühendislik Fakültesi, Makina Mühendisliği Bölümü, İmir
}

Geliş Tarihi (Received Date): 20.05.2020

Kabul Tarihi (Accepted Date): 04.09.2020

$\ddot{\mathbf{O z}}$

Kardan milleri motordan aldiğg torku ve dönme hareketini akslar üzerinden arka tekerleklere ileten bir aktarma elemanıdır. Yüksek tork taşıma gereklilikleri nedeniyle alt parça tasarımları bu beklentilere uygun olarak gerçekleştirilmektedir. Taşıması beklenen tork kapasiteleri aracın motor torku, aracın kullanım yeri, şanzıman tipi gibi birçok faktöre bağlı olarak analitik bir yaklaşımla belirlenmektedir. Kardan milinin gerçek kullanım koşullarında karşılaması gereken tork seviyeleri ise ancak test ortaminda kardan mili üzerinden gerinim verisinin toplanmasiyla ortaya çıkabilmektedir. Ticari olarak ulaşılabilen ölçüm sistemleri, kardan mili üzerinde ortaya çıkan torku ölçebilmemizi sağlasa da, bu sistemlerin yüksek maliyetleri ve saha koşullarında çalışmaya ve enstrümantasyona uygun olmamalart sahada bu ürünlerin kullanımını zorlaştırmaktadır. Belirli test rotalarında ve belli senaryoların koşturulmasında bu sistemlerin kullanıldı ğl görülmektedir. Bu çalışmada, kardan mili üzerinden tork ölçümü gerçekleştirebilecek bir sistemin tasarımı ve üretimi gerçekleştirilmiştir. Böylece kardan miline entegre şekilde sahada koşabilecek ve anlık olarak ölçüm gerçekleştirebilecek düşük maliyetli bir ölçüm sistemi geliştirilmiştir. Çalışma kapsamında sistemin ölçüm doğruluğu belirlemek amacılla ürünün fonksiyonel limitlerine uygun değerler için statik torsiyon testleri gerçekleştirilmiştir. Test cihazı ve ölçüm sistemi tekrarlayan testlerle karşılaştırılmıştır. Karşılaştırmalar sonucunda ölçüm sisteminden okunan tork değerlerinin test cihazından uygulanan değerlerle maksimum \%5'lik bir hata payı içinde uyumlu olduğu görülmüştür.

Anahtar kelimeler: Kardan mili, tork ölçümü, statik torsiyon testi.

\footnotetext{
* Sedat TARAKÇI, s.tarakci@ tirsankardan.com.tr, https://orcid.org/0000-0002-9125-5919 Oğuzhan ALDEMIR, o.aldemir@tirsankardan.com.tr, https://orcid.org/0000-0002-3471-5034 Efe IŞIK, efe_isik@yahoo.com, https://orcid.org/0000-0001-7657-317X

Serhan ÖZDEMIR, serhanozdemir@iyte.edu.tr, https://orcid.org/0000-0003-2320-9213
} 


\title{
Design and production of a torque measurement system on a driveshaft
}

\begin{abstract}
The driveshafts are responsible for transmitting power and rotational movement from the engine to the rear axles. Driveshaft's subcomponents are designed to fullfill high torque transmission requirements. Expected torque tranmission capability is calculated analitically regarding engine torque, transmission type and type of vehicle. However actual torque transmission level can only be detected by data acqusition from driveshaft in test applications. Although COTS measurement systems allow us to measure the torque generated on the drivehshaft, these systems are expensive and instrumentation of these system are not suitable to operate in field conditions. These systems are required for change test routes and for running certain scenarios. In this study, the design and the production of a system in order measuring torque on driveshaft has been realized. Thus, a low-cost measurement system that can run on the field which is integrated with the drivehaft and take measurements instantly has been developed. Static torsion tests were carried out for values that are in accordance with the functional limits of the driveshaft for the measurement accuracy. The results of verified test bench and measuring system were compared with repeated tests. Comparisons show that the torque values read from the measuring system appears to be compatible with the values applied by the verified test system within a 5\% margin of error.
\end{abstract}

Keywords: Driveshaft, torque measurement, static torsion test.

\section{Giriş}

Otomotiv endüstrisinde kullanıcıların beklentileri her geçen gün artmaktadır. Çevresel kaygılarla da birlikte otomobil üreticileri araçlarını hafifletmek için çalışmakta ve tedarikçilerini de bu yönde çalışmaya yönlendirmektedir. Daha hafif kardan mili tasarım ve uygulamalarının güç aktarım organları arasında yer alması bu doğrultuda beklenmektedir. $\mathrm{Bu}$ aşamada kullanılan ürünlerin gerçek çalışma koşulları hakkında bilgi sahibi olmak, tasarımların sınır koşullarını belirlemede ve tasarımlara bu doğrultuda yön vermede önem kazanmaktadır.

Kardan millerinde de önemli tasarım parametrelerinden olan fonksiyonel tork limitleri genellikle aracın motor özellikleri, aracın kullanım amacı, şanzımanı ve aktarma oranları gibi belli parametreler üzerinden analitik yaklaşımlarla belirlenmektedir. Aracın sahada karşılaştığı gerçek durumlarda veya gerçek durumların simule edildiği test alanlarında tork verisinin toplanabilmesi ise tasarımların doğrulanması ve geliştirilmesi açısından önemlidir. Ticari olarak bu çalışmaları gerçekleştirmekte kullanılabilen ölçüm sistemleri bulunsa da, zorlu çevresel koşullarda çalışmaya uygun olmamaları, enstrümantasyonlarının uzmanlık gerektirmesi ve yüksek maliyetleri bu dezavantajları giderecek bir ölçüm sistemi üzerinde çalışma ihtiyacını doğurmuştur.

Kardan mili üzerinden farklı tork ölçüm uygulamaları bulunmaktadır. J.D. Turner, Development of a Rotating Shaft Torque Sensor for Automotive Applications isimli yayınında kapasitif bir tork ölçüm sensörü yardımıyla dönen bir şaft üzerinden tork 
ölçümünün nasıl yapılacağına dair geliştirilen bir teknik ve sensörün çalışma prensipleri ortaya koymuştur [1]. Bir diğer çalışmada Richard A. Beth ve arkadaşları burulma altındaki bir şaft üzerinden alınan tork ölçümüne dair bir teknik üzerinde çalışmışlardır [2]. Marukami ve arkadaşları kablosuz bir gerinim ölçüm sistemi üzerinde çalışmışlardır ve bunu araç jantları üzerinde uygulamışlardır [3]. Nagayama ve arkadaşları ise bir gerinim ölçüm sistemi üzerinde çalışmış ve güç tasarrufu sağlamak için standart gerinim ölçerler yerine $4.5 \mathrm{k} \Omega$ 'luk gerinim ölçerler kullanılmıştır [4]. Vanieiev ve arkadaşları temassız bir tork ölçüm sistemini torsiyonel dinamometreler üzerinde uygulamışlardır ve $\pm 100 \mathrm{Nm}$ içinde ölçüm almışlardır [5].

Wang Yi'nin çalışmasında bir elektrik motoru çıkışına alın yüzeyiyle bağlanan bir şaft ve şaftın üzerinden tork verisinin basit şekilde nasıl alınacağı bahsedilmiştir. Uygulamanın karmaşık gözükmemesi ve ölçüm sistemi maliyetlerinin düşük olması avantaj olarak görünse de sistemin yol koşullarında kullanılamayacak kadar büyük olması ve enstrümantasyonu saha koşullarında uygulanabilirliği zorlaştırmaktadır [6].

$\mathrm{Bu}$ çalışmada, kardan mili üzerinden tork ölçümü gerçekleştirebilecek bir sistemin tasarımı ve üretimi gerçekleştirilmiştir. Böylece kardan miline entegre şekilde sahada koşabilecek ve anlık olarak ölçüm gerçekleştirebilecek düşük maliyetli bir ölçüm sistemi geliştirilmiştir.

Çalışma kapsamında sistemin ölçüm doğruluğu belirlemek amacıyla ürünün fonksiyonel limitlerine uygun değerler için statik torsiyon testleri gerçekleştirilmiştir. Test cihazı ve ölçüm sisteminden alınan sonuçlar tekrarlayan testlerle karşılaştırılmıştır. Karşılaştırmalar sonucunda ölçüm sisteminden okunan tork değerlerinin test cihazından uygulanan değerlerle maksimum \%5'lik bir hata payı içinde uyumlu olduğu görülmüştür.

\section{Tork ölçüm sistemi}

Ticari ölçüm sistemleri üreten firmaların aks ve kardan milleri açısından gerçekleştirdiği sistemler mevcuttur [7, 8]. Gerinim verisi kardan mili borusu üzerine yerleştirilen gerinim ölçerler vasıtasıyla toplanmıştır. Kardan mili üzerinde gerinim ölçümüne uygun noktalar belirlenmiştir. Aynı zamanda bu noktaların tork ile ilişkilendirilebilecek seviyede gerinim değişimine uğraması gerekmektedir. Şekil 1 ve Şekil 2'de iki farklı noktada gerçekleştirilen uygulamalar görülmektedir.

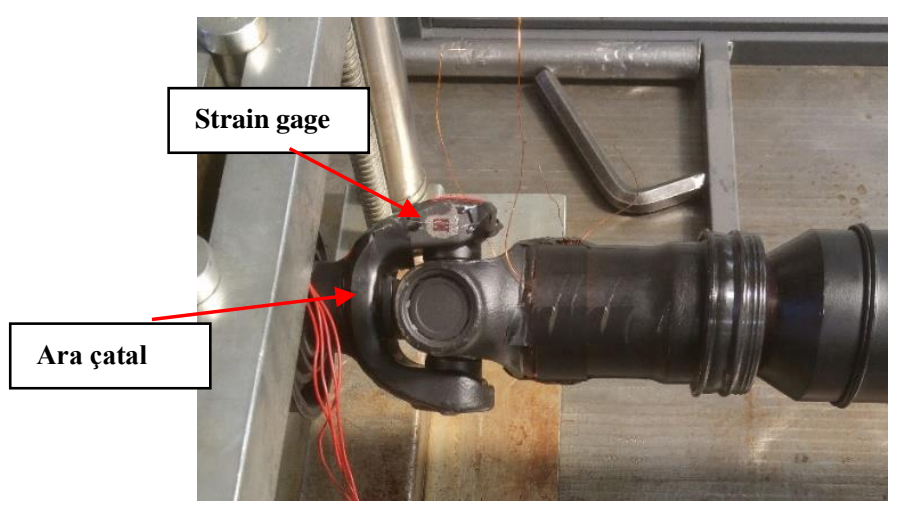

Şekil 1. Ara çatal üzeri gerinim ölçer uygulaması. 


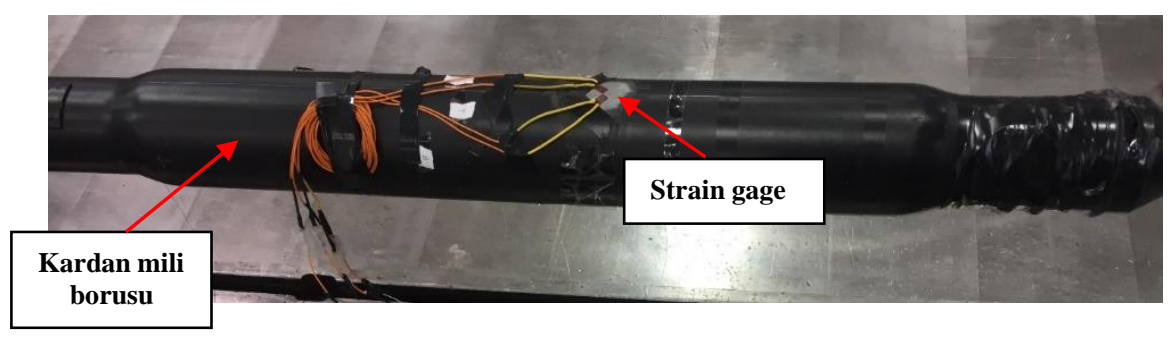

Şekil 2. Kardan mili borusu üzeri gerinim ölçer uygulaması.

Gerinim ölçerlerin (strain gage) bağlanacağı yüzeylerin boya ve kaplaması kaldırıldıktan sonra, zımparalanarak temizlenmiştir. Yüzeyler alkolle yıkandıktan sonra gerinim ölçer yapıştırılmıştır. Ölçümler, numune üzerinden, Şekil 3'te gösterilen diyagramı takip ederek gerçekleştirilmiştir [9].

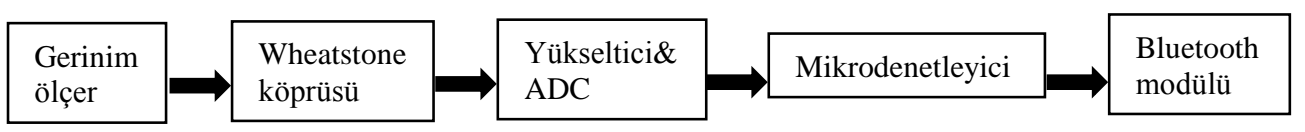

Şekil 3. Gerinim ölçüm diyagramı.

Çalışmada $350 \Omega$ tork tipi gerinim ölçerle yarım köprü üzerinden ve $1000 \Omega$ genel kullanım gerinim ölçerlerle yarım köprü üzerinden veri toplanmıştır. Yarım köprü uygulaması Şekil 4'te gösterilmektedir. İlk uygulamada ticari bir op-amp üzerinden sinyal güçlendirilmiştir [10]. Op-amp kazanç değeri 1000 olarak belirlenmiştir. Opamp'ın çıkışındaki sinyal RC tip bir alçak geçiren filtreden geçirilmiştir. Sonrasında bir mikrodenetleyiciye beslenmiştir. Mikrodenetleyici içinde analog dijital çevrimi gerçekleştirilmiştir ve kablosuz bir iletişim modülü üzerinden veriler okunmuştur.

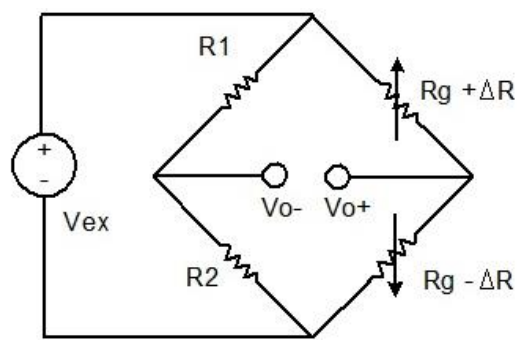

Şekil 4. Wheatstone köprüsü.

Veri toplama çalışmalarına paralel şekilde alternatif bir tork ölçüm sistemi geliştirilmiştir. Wheatstone köprüsü çıkışında sinyal, içinde analog dijital çevrimi de gerçekleştiren bir entegreye beslenmiştir. Bu sistem için op-amp kazanç değeri 128 olarak belirlenmiştir [11]. Sonrasında veriler bir mikrodenetleyici üzerinden kablosuz iletişim modülüne gönderilmiştir. Sistemin toplam güç ihtiyac1 $60 \mathrm{~mW}$ seviyelerinde olmuştur. Farklı kablosuz iletişim modüllerinin devreye alınmasıyla bu ihtiyaç $40 \mathrm{~mW}$ seviyelerine kadar düşürülmüştür. Şekil 5 'te ölçüm devresinin görüntüsü yer almaktadır.

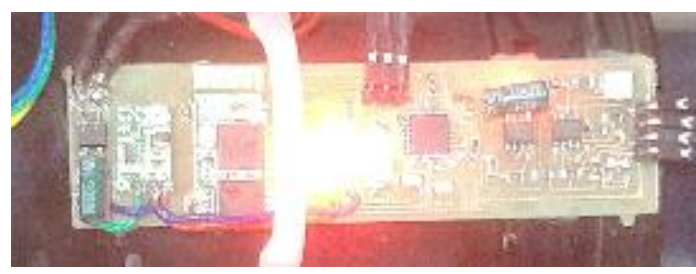

Şekil 5. Tork ölçüm devresi kartı. 


\section{Statik torsiyon testi}

Kardan milinin farklı tork yüklemelerindeki gerinim seviyelerini belirlemek için numune kardan milleri test cihazı üzerine konumlandırılır. Test cihazının görünümü Şekil 6'da verilmiştir.

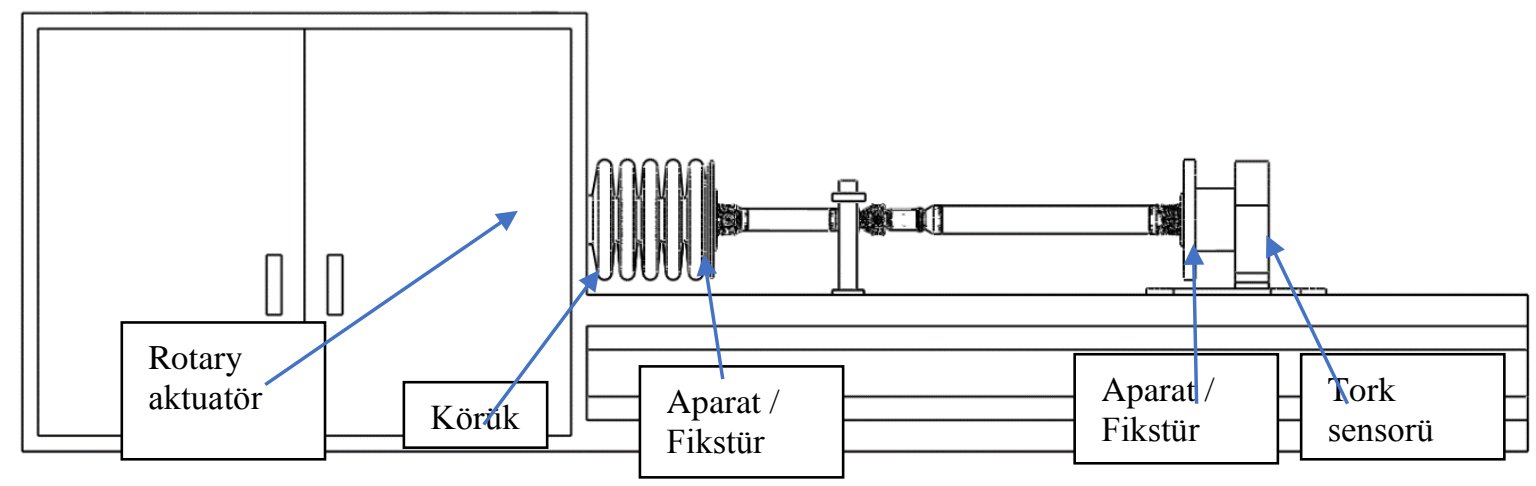

Şekil 6. Statik torsiyon test cihazı[12].

Test numunesi, statik torsiyon test cihazına her iki flanşından da cıvatalar ile bağlanır ve belli bir tork ile sıkılır. Bağlantının kontrolleri sağlanıp güvenli olarak bağlandığından emin olunduktan sonra koruma kapakları takılır. Test cihazında istenilen adım ve artış hızlarıyla 5000 Nm'ye kadar tork yüklemesi yapılabilmektedir. İstenildiğini takdirde belli bir frekansta istenilen dalga formunda periyodik yüklemeler de gerçekleştirilmektedir.

Bu çalışma kapsamında, kullanılan kardan milinin dayanım sınırları göz önüne alınarak, $500 \mathrm{Nm}$ artışlarla 3000Nm'ye kadar kademeli bir tork yüklemesi gerçekleştirilmiş, sonrasında kademeli azalışlarla ters yönde $2500 \mathrm{Nm}$ yükleme yapılmıştır. Son olarak kademeli olarak yükleme kaldırılmış ve 0 noktasında test tamamlanmıştır. Sonuçların güvenilirliği adına test tekrarları gerçekleştirilmiştir.

\section{Veri toplama çalışmaları}

Gerinim ölçerler tork ölçüm sistemi altında bahsedildiği gibi kardan mili üzerine konumlandırılmıştır ve kardan miline tork uygulanarak ölçümler alınmıştır. İlk olarak ara çatal adlı parça üzerinden ölçümler alınmıştır. Sonuçlar Şekil 7'de gösterilmiştir.
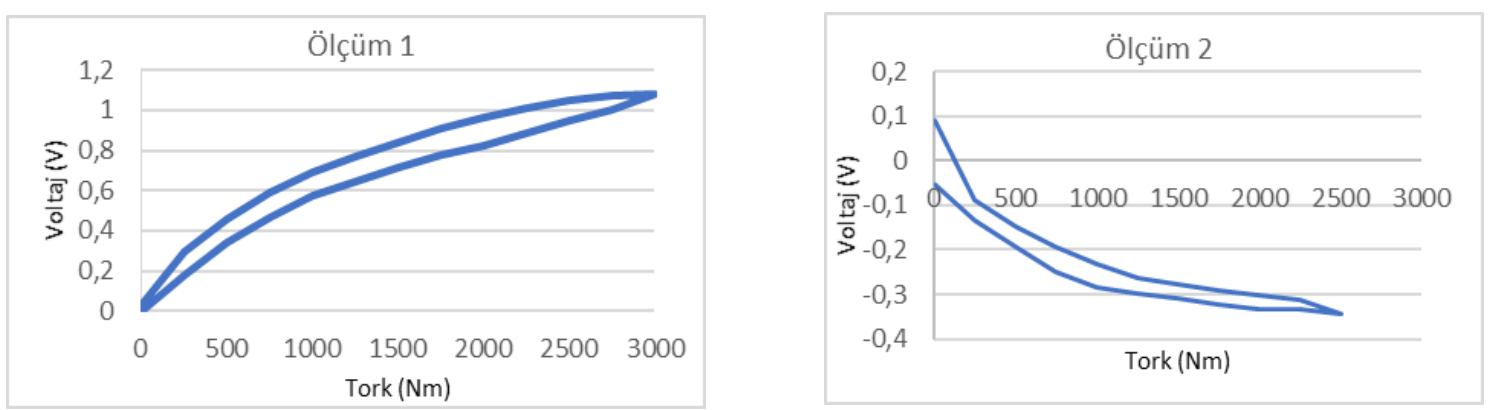

Şekil 7. Ara çatal üzerinden yapılan tork ölçüm sonuçları. 
Sonuçlar değerlendirildiğinde, ölçüm sonuçlarının doğrusal bir artış göstermediği görülmüştür. Aynı zamanda görülen yüksek histerezis nedeniyle tekrar edilebilirlik açısından istenen performans elde edilememiştir. Ayrıca sonlu elemanlar analizlerine göre yapılan incelemede, gerinim ölçer uygulanan bölgede gerilim değişimlerinin çok düşük olduğu ve bu nedenle tork ve voltaj arasındaki ilişkinin mevcut ölçüm yöntemimizle istenilen doğrulukla kurulamayacağı anlaşılmıştır [12]. Şekil 8'de ara çatal parçası için sonlu elemanlar analiz sonucu gösterilmektedir.

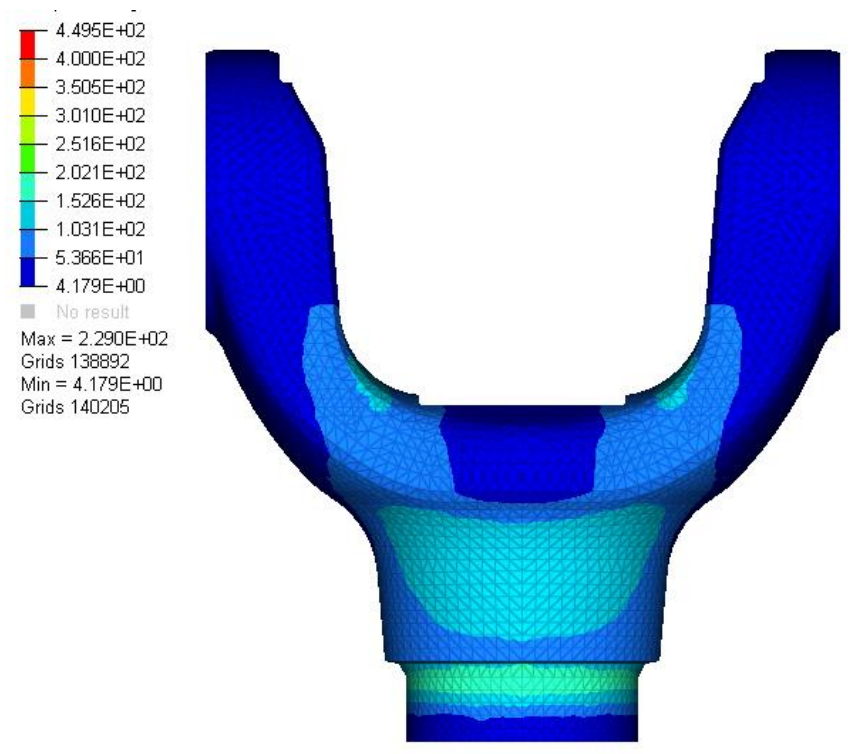

Şekil 8. Ara çatal parçası sonlu elemanlar analiz sonuçları.

Burulma teorisine göre de tork altında çalışan dairesel olmayan parçaların, dairesel parçalara göre gerilme dağılımlarının belirlenmesi çok daha karmaşıktır. Bunun nedeni dairesel olmayan parçalarda meydana gelen çarpılmadır [13]. Bu gerekçelerle ara çatal üzerinde gerçekleştirilen veri toplama çalışmaları sonlandırılmıştır.

Kardan mili borusu üzerine uygulanan gerinim ölçerle test tekrarlanmıştır. Test sonuçları Şekil 9'de görülmektedir.
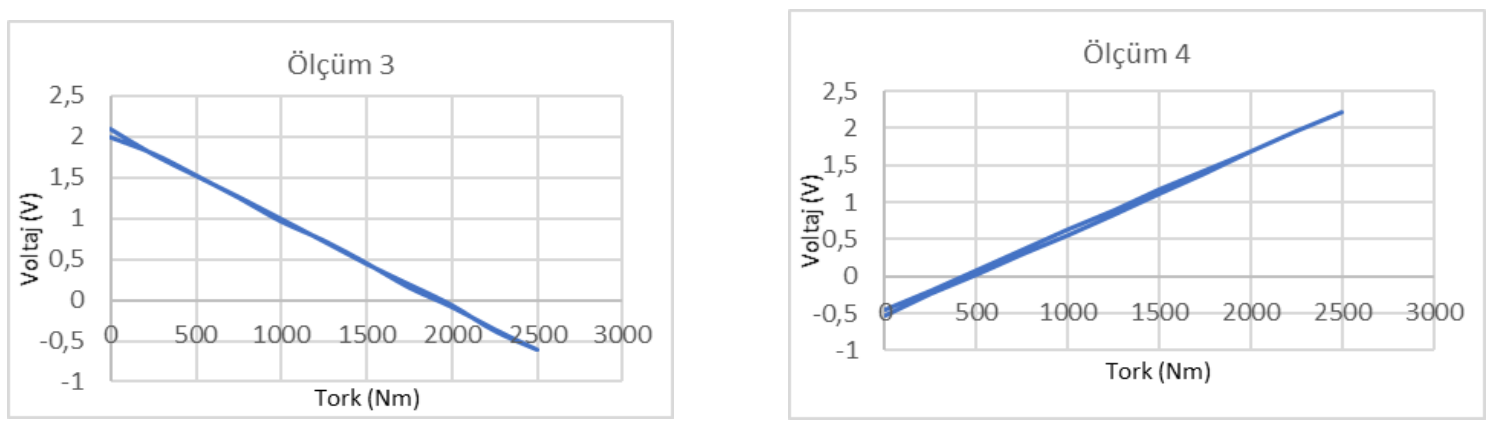

Şekil 9. Kardan mili borusu üzerinden tork ölçüm sonuçları.

Elastik bölgede çalıştığımız için tork ile gerinimin doğrusal bir ilişki göstermesi beklenmektedir [13]. Uygulamada ise histerezis kaynaklı lineer olmayan durumlar görülebilmektedir. Ölçüm sisteminden elde edilen voltaj değişimlerinin de gerinim verisi ile doğrusal bir ilişkisi olması beklenmektedir. Bununla birlikte gage faktörü 
katsayısına bağlı olarak doğrusal olmayan sonuçlar elde edilebilmektedir. Bunların yanında gerinim ölçerlerin montajı, op-amp'taki offset değerleri, kablolama, sicaklık değişimi gibi faktörler doğrusallığı etkilemektedir. Bunun yanında elektronik gürültüye de neden olmaktadır. Tüm bu faktörler göz önüne alındığında, kardan mili borusu üzerinde gerçekleştirilen ölçüm sonuçlarının doğrusal bir grafik oluşturduğu ve tekrar edilebilirlik açısından uygun olduğu belirlenmiştir. Bu ölçümlerin ardından uygulanan tork ile voltaj değerleri arasında bir korelasyon oluşturulmuştur. Tekrarlanan ölçümlerde kademeli olarak tork değeri artırılmış ve $2000 \mathrm{Nm}$ değerine kadar çıkılmıştır. Sonrasında kademeli olarak tork değeri azaltılarak sıfırlanmıştır. Şekil 10'da verilen ölçüm değerleri incelendiğinde gürültü seviyelerinin çok yüksek olduğu görülmüştür. Gerçekleştirilen çalışmalarla bir alçak geçiren filtre uygulanmış ama buradan istenen sonuçların alınamadığı görülmüş̧ür.

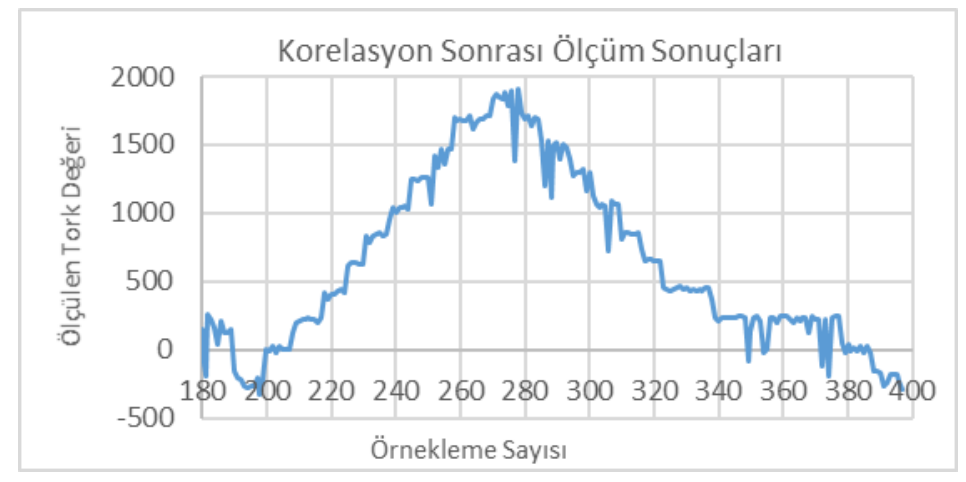

Şekil 10. Korelasyon sonrası ölçüm sonuçları.

Test sonuçlarında görüldüğü gibi yüksek oranda elektronik gürültü oluşu sürmektedir. $\mathrm{Bu}$ gürültü hedeflenen ölçüm doğruluğunun yakalanmasını engellemektedir. $\mathrm{Bu}$ sonuçlar doğrultusunda ölçüm sisteminde değişikliklere gidilmiştir. Kullanılan op-amp entegresi değiştirilerek 10 bit üstü analog dijital çevirici içeren bir op-amp ölçüm sistemine dahil edilmiştir [11]. Ayrıca kullanıma alınan entegre ile uyumlu $1000 \Omega$ genel kullanım gerinim ölçerleri eksenle $45^{\circ}$ 'lik açı yapacak şekilde konumlandırılarak kullanılmıştır. Şekil 11'da test uygulaması görülmektedir.
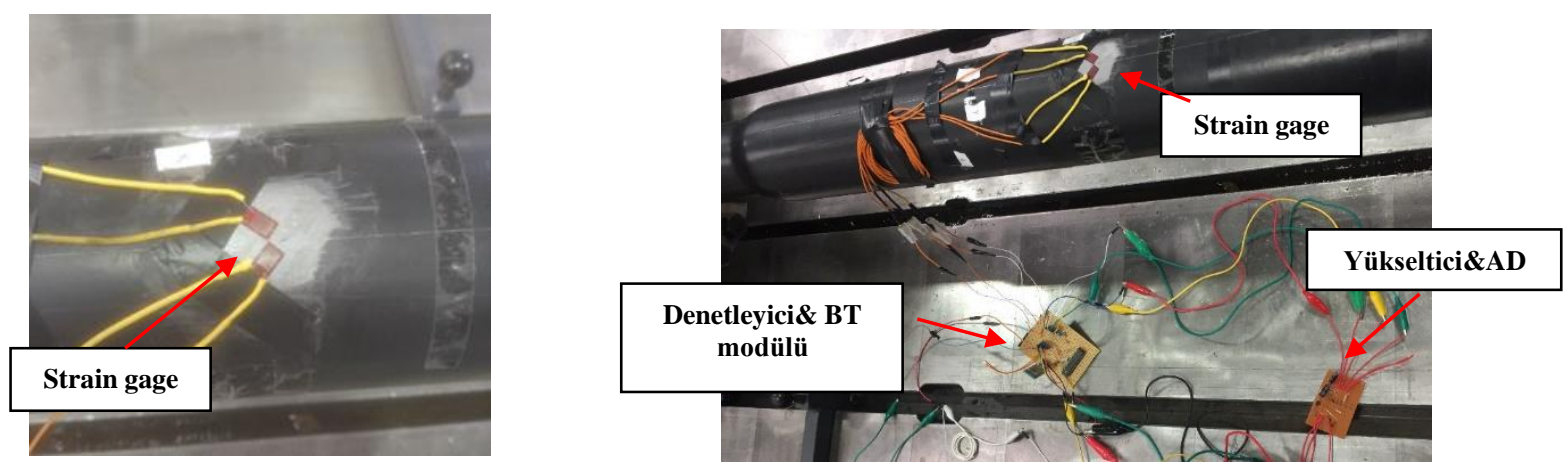

Şekil 11. Revize tork ölçüm devresi ile test uygulaması.

Ölçüm entegresi ve veri iletim devresi iki ayrı devre olarak üretilmiştir ve şekil 12'de gösterilmektedir. 

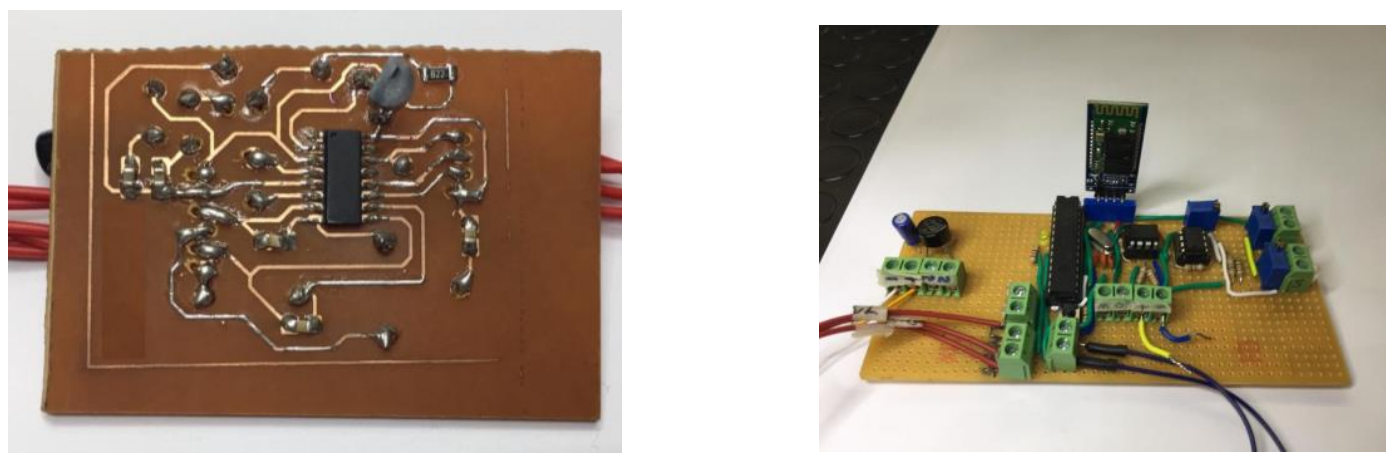

Şekil 12. Yükseltici\& Analog dijital cevirici entegre devresi (solda) ve veri iletim devresi (sağda).

$\mathrm{Bu}$ değişikliklerin ardından tork verisi toplama testleri yeniden gerçekleştirilmiştir. Test sonuçları Şekil 13'de görülmektedir.

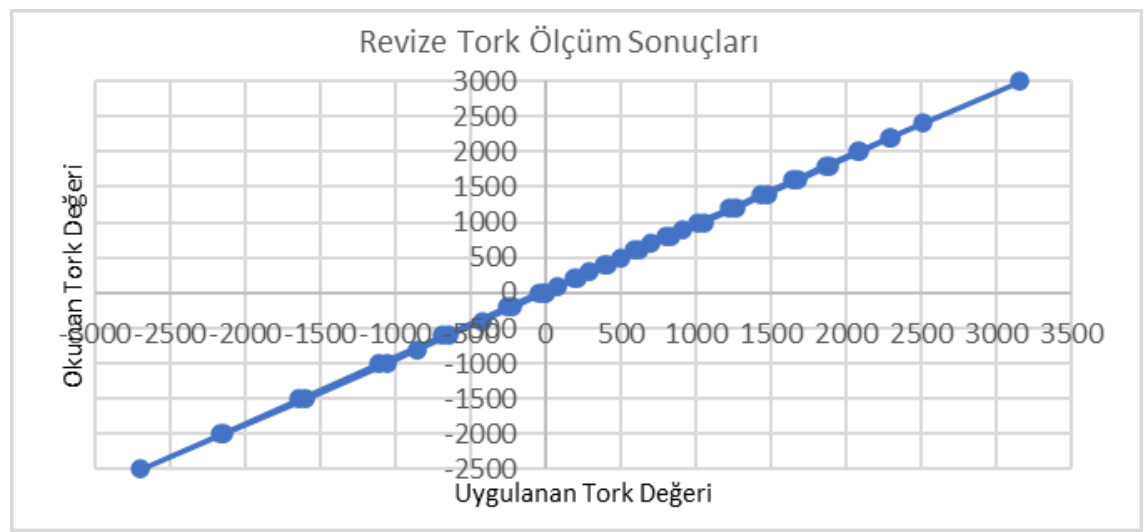

Şekil 13: Tork doğrulama test sonuçları

\section{Sonuçlar ve tartışma}

Veri toplama ve kalibrasyon testleri sonucunda sistemin doğrulama testi gerçekleştirilmiştir. 0-3000 Nm arasında $250 \mathrm{Nm}$ 'lik artışlarla test başlamış, sonrasında $250 \mathrm{Nm}$ azalışlarla $0 \mathrm{Nm}$ 'ye dönülmüştür. Sonrasında ters yönde tork uygulanmıştır. $500 \mathrm{Nm}$ artışlarla $2500 \mathrm{Nm}$ 'ye kadar gidilmiş, tekrar $500 \mathrm{Nm}$ kademeli azalışlarla test tamamlanmıştır. Testlerde okunan değerlerle uygulanan değerler Şekil 14'de görülmektedir.

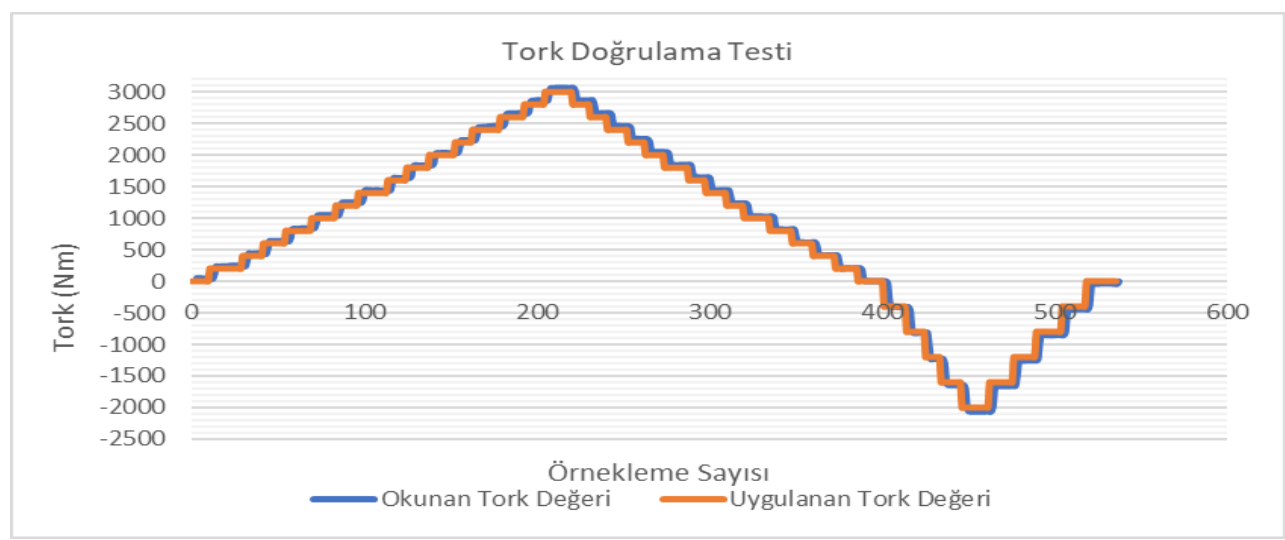

Şekil 14. Tork doğrulama testi. 
Test sonuçları değerlendirildiğinde, çalışmanın başında hedeflenen ölçüm sonuçları ile statik torsiyon cihazından uygulanan değerler arasındaki \%5 lik sapmanın sağlandığı görülmüştür. Sistemin tekrar edilebilirliği testlerle doğrulanmıştır. Gürültü seviyeleri azaltılarak sistem hassasiyeti arttırılmıştır.

Firma içinde mühendisliği ve imalatı gerçekleştirilen bu kartlar, Şekil 12'da görüleceği gibi, tek bir prototip pcb üzerinde toplanmış ve kompakt hale getirilmiştir. Pahalı ticari test cihazlarıyla yukarıda yapılan karşılaştırmaların 1 şı ğında sapmaların $\% 5$ 'in altında kalmasıyla, test merkezinde gerçekleşecek bir grup testte bu sistemin kullanılabileceği anlaşılmıştır. Bunun yanında firmaların düşük maliyetlerle kendi ölçüm ihtiyaçlarına dönük ölçüm sistemi geliştirmelerinin mümkün olduğu ve direk ihtiyaca dönük çözümlerin geliştirilebileceği ortaya konmuştur.

Bundan sonra gerçekleştirilecek çalışmalarda yüksek hızlardaki periyodik yüklemelerde ölçüm sisteminin doğrulaması gerçekleştirilecek ve dinamik durumlardaki performansı simule edilecektir.

\section{Teșekkür}

Kardan Ar-Ge Merkezi'ne ve Test Merkezi'ne bu çalışmanın gerçekleştirilmesindeki katkılarından dolayı sonsuz teşekkürlerimizi sunarız.

\section{Kaynaklar}

[1] Turner, J., Development of a rotating-shaft torque sensor for automotive applications, IEE Proceedings D (Control Theory and Applications), IET, (1988).

[2] Beth, R. A., ve Meeks, W. W., Magnetic measurement of torque in a rotating shaft, Review of Scientific Instruments, 25(6), 603-607, (1954).

[3] Murakami, Y., et al., Data acquisition by a small portable strain histogram recorder(mini-rainflow corder) and application to fatigue design of car wheels, Technical Research Centre of Finland, Fatigue Design 1998., 2: 373-383, (1998).

[4] NagaÝama, T., et al., Wireless strain sensor development for civil infrastructure. Presented at INSS, (2004.6), (2004).

[5] Vanieiev, S.M., et al., Data Measuring System for Torque Measurement on Running Shafts Based on a Non-Contact Torsional Dynamometer, (2019).

[6] CN209264167.

[7] Hoeppner, C., et al., 3.5 Telemetering Systems, (2006).

[8] Telemetry, K., Telemetric steering wheel KMT-CLS.

[9] Measuring Strain with Strain Gages NI.

[10] Instruments, T., Lm741 operational amplifier. LM741 datasheet, May, (1998).

[11] Hx711, D., 24-Bit Analog-to-Digital Converter (ADC) for Weigh Scales. AVIA Semiconductor, (2014).

[12] Akkas, O., et al., A Correlation Study of an FEA Method Developed for Heavy Duty Driveshaft Applications, The Eurasia Proceedings of Science Technology Engineering and Mathematics, 7, 315-320, (2019).

[13] Hibbeler, Russell Charles, Mechanics of Materials, 84, 221, Prentice Hall Pearson, (2010). 